\title{
A Clinical Investigation of Motivation to Change Standards and Cognitions about Failure in Perfectionism
}

\author{
Sarah J. Egan and Jan P. Piek \\ Curtin University, Perth, Australia \\ Murray J. Dyck \\ Griffith University, Brisbane, Australia \\ Clare S. Rees and Martin S. Hagger \\ Curtin University, Perth, Australia
}

\begin{abstract}
Background: Clinical perfectionism is a transdiagnostic process that has been found to maintain eating disorders, anxiety disorders and depression. Cognitive behavioural models explaining the maintenance of clinical perfectionism emphasize the contribution of dichotomous thinking and resetting standards higher following both success and failure in meeting their goals. There has been a paucity of research examining the predictions of the models and motivation to change perfectionism. Motivation to change is important as individuals with clinical perfectionism often report many perceived benefits of their perfectionism; they are, therefore, likely to be ambivalent regarding changing perfectionism. Aims: The aim was to compare qualitative responses regarding questions about motivation to change standards and cognitions regarding failure to meet a personal standard in two contrasting groups with high and low negative perfectionism. Negative perfectionism refers to concern over not meeting personal standards. Method: A clinical group with a range of axis 1 diagnoses who were elevated on negative perfectionism were compared to a group of athletes who were low on negative perfectionism. Results: Results indicated that the clinical group perceived many negative consequences of their perfectionism. They also, however, reported numerous benefits and the majority stated that they would prefer not to change their perfectionism. The clinical group also reported dichotomous thinking and preferring to either keep standards the same or reset standards higher following failure, whilst the athlete group reported they would keep standards the same or set them lower. Conclusions: The findings support predictions of the cognitive behavioural model of clinical perfectionism.
\end{abstract}

Keywords: Perfectionism, cognitive behavioural model, qualitative, cognition.

Reprint requests to Sarah Egan, School of Psychology and Speech Pathology, Curtin University, GPO Box U1987, Perth, WA 6845, Australia. E-mail: s.egan@curtin.edu.au 


\section{Introduction}

Perfectionism is a transdiagnostic process as it is elevated in anxiety disorders, eating disorders and depression (Egan, Wade and Shafran, 2011). Perfectionism predicts poorer response to treatment (Egan et al., 2011) and predicts higher levels of comorbidity (Bieling, Summerfeldt, Israeli and Antony, 2004). It has, therefore, been suggested that targeting perfectionism may result in symptomatic relief across a number of domains (Bieling et al., 2004). The predominant definition of perfectionism has been based on the Multidimensional Perfectionism Scales (FMPS; Frost, Marten, Lahart and Rosenblate, 1990; HMPS; Hewitt and Flett, 1991). The issue of whether perfectionism can be considered to have positive characteristics has been contentious in the literature. It has been demonstrated in a review that the positive achievement striving aspect of perfectionism is associated with positive adjustment (Stoeber and Otto, 2006). There is also, however, evidence that MPS subscales representing positive striving are correlated with symptoms of eating disorders and depression (Egan et al., 2011). Negative perfectionism has generally been referred to as concern over failure to meet standards. Shafran, Cooper and Fairburn (2002) proposed a clinicallyrelevant definition of perfectionism in their model of clinical perfectionism that emphasizes overdependence of self-evaluation on the determined pursuit of demanding standards. This model has recently been updated to include a number of cognitive and behavioural factors thought to maintain clinical perfectionism, such as dichotomous thinking (Shafran, Egan and Wade, 2010). Another maintaining factor is the individual re-setting their standards higher, following both success and failure. This factor is thought to maintain the individual in a "nowin" situation, where they continually try to achieve high standards. The model is useful in providing a clinically relevant formulation of perfectionism (Egan et al., 2011).

Few studies have examined perfectionism using qualitative methodology. It is useful as it can give a rich and in-depth understanding of an area that may not always be captured by quantitative methods (Denzin and Lincoln, 2000). Such methods may also be useful in further developing theory through "theory-building" and compliment quantitative data (Hagger and Chatzisarantis, 2011) in shedding further light on the nature of perfectionism. Riley and Shafran (2005) used a qualitative approach with 15 individuals who were defined as having clinical perfectionism. Participants were asked questions about striving towards goals, whether they thought they had ever reached their own standards, and their scheme for self-evaluation. Riley and Shafran reported the core themes from the data as self-imposed unhelpful standards, continually striving, and striving despite negative consequences. They also reported several themes that indicated some of the mechanisms that maintain clinical perfectionism, including: self-critical reaction to failure, positive reaction to success, biases in thinking, rules and rigidity, avoidance, escape, safety behaviour, procrastination, and fear-driven and value-driven behaviour. This study was useful in examining some of the maintaining factors of the model of clinical perfectionism (Shafran et al., 2002), although it did not examine motivation to change perfectionism.

There have been other qualitative studies that have examined perfectionism in students. Neumeister (2004) investigated perfectionism in 12 "gifted" college students in an interview about academic success and failure. Six students who scored highly on HMPS self-oriented perfectionism (SOP), and six who scored highly on socially-prescribed perfectionism (SPP) were selected from a pool of 290 students. Students high on SOP reported themes of taking pride in their successes, making internal attributions for success and, when they failed, 
making situation-specific attributions. In contrast, students high on SPP reported themes of minimizing their successes, making internal attributions for failure, and overgeneralizing the consequences of failure. Another study interviewed nine college students using a qualitative interview to assess the "best and worst" things about perfectionism (Rice, Bair, Castro, Cohen and Hood, 2003). Students who reported high scores on the FMPS subscale of Personal Standards reported less distress when they did not achieve a personal standard, whereas students who scored highly on the Concern over Mistakes subscale of the FMPS were more likely to report distress. The results of these qualitative studies are in line with quantitative results that indicate SOP and Personal Standards are often associated with less distress than SPP and Concern over Mistakes (Egan et al., 2011).

To date, there have been no studies investigating motivation to change perfectionism. The importance of addressing motivation to change has been noted by Wilson and Schlam (2004) who stated: "If psychological treatments are to be maximally effective, they must include empirically supported strategies for reinforcing and enhancing patients' motivation to change" (p. 370). It is hypothesized that individuals with perfectionism are likely to perceive it having many benefits, thus may be ambivalent about change. There were two aims of the current research. First, to examine motivation to change perfectionism. Second, to explore the maintaining factors proposed in the cognitive-behavioural model of clinical perfectionism (Shafran et al., 2002, 2010) by examining reactions to failure, and re-setting of standards following failure. To date no research has investigated these areas using qualitative methodology in a clinical group. A qualitative approach was chosen to provide rich data on experiences and in-depth perceptions of this group that are not captured by quantitative studies, which may not have the flexibility to investigate differences in interpretation of motivation to change perfectionism. The study included an athletic group as a comparison that was low on negative perfectionism to help examine why there may be differences compared to a clinical group. The rationale for including athletes is that, similar to clinical groups, they have been found to set high personal standards, but to score lower on negative perfectionism (e.g. Terry-Short, Owens, Slade and Dewey, 1995). Consequently, athletes provide a logical comparison group to a clinical group to help identify the factors associated with, and the mechanisms underpinning, the negative aspects of perfectionism.

\section{Method}

\section{Participants}

Participants were selected from a larger sample of 40 clinical participants (72\% females) and 111 athletes (34\% females) that was the sample in a previous study assessing dichotomous thinking in perfectionism (Egan, Piek, Dyck and Rees, 2007). Ten participants who scored the highest on negative perfectionism on the PANPS in the clinical group and 10 who scored the lowest on negative perfectionism in the athlete group were contacted via telephone and asked to participate in a subsequent study that involved an interview. All participants agreed to complete the study.

There were 10 individuals in the clinical group (80\% females) and 10 athletes $(60 \%$ females). Age was not significantly different between the clinical group $(M=38.40$, $S D=10.69)$ and the athletes $(M=41.70, S D=8.56)$. The clinical group was recruited from the postgraduate psychology training clinic at Curtin University. Inclusion criteria were a 
DSM-IV diagnosis of an anxiety and/or depressive disorder. Exclusion criteria were psychosis and severe suicidal ideation. Diagnoses were determined by the Structured Clinical Interview for DSM-IV Disorders (Version 2.0/Patient Form) (SCID-I/P; First, Spitzer, Gibbon and Williams, 1996).

Co-morbidity in the clinical group was high, with an average of 4.1 diagnoses per person; $70 \%$ of the sample had two or more disorders, $70 \%$ three or more disorders, $50 \%$ four or more disorders, and $40 \%$ five or more disorders. Axis 1 diagnoses included Major Depression (80\%), Social Phobia (60\%), Obsessive Compulsive Disorder (20\%), Generalized Anxiety Disorder (30\%), Panic Disorder (10\%), Post Traumatic Stress Disorder (10\%), and Alcohol Abuse (10\%). Axis II diagnoses included Obsessive-Compulsive Personality Disorder (PD) (50\%), Paranoid PD (30\%), Avoidant PD (30\%), Dependent PD (20\%), Borderline PD (20\%), Narcissistic PD (20\%), and Schizoid PD (20\%).

Inclusion criteria for athletes were competition in one or more triathlon races in the past 12 months. The majority of the sample could be considered amateur "age group" athletes rather than at a professional level; however, in response to a question asking if they were a "novice" or "elite" athlete, $57 \%$ stated novice, and $43 \%$ elite. The athletes were very experienced competitors, completing an average of $10(S D=3.30)$ triathlons per year (range 3-18) and total number of triathlons completed was an average of $53(\mathrm{SD}=35.8$, range 9-150).

\section{Measures}

The Positive and Negative Perfectionism Scale (PANPS; Terry-Short et al., 1995). The PANPS is a 40-item self-report scale that measures positive and negative perfectionism. It has good internal consistency, ranging from .83 - .88 (Haase, Prapavessis and Owens, 1999, 2002). In this study, Cronbach's alpha was .85 for positive perfectionism and .87 for negative perfectionism. The questionnaire comprises 20 items on each subscale and responses made on 5-point scales ranging from 1 (strongly disagree) to 5 (strongly agree). There are 20 items on each subscale. An example of a positive item is: "I like the challenge of setting very high standards for myself" and an example of a negative item is: "When I achieve my goals I feel dissatisfied".

Structured Clinical Interview for DSM-IV axis I disorders (SCID-I/P, Version 2.0; First et al., 1996) and Structured Clinical Interview for DSM-IV Personality Disorders (SCID-II, Version 2.0; First et al., 1994). The SCID I/P was used to assess which DSM-IV diagnoses the clinical participants met. The SCID-I/P has moderate reliability, with median test-retest reliability of .69, and interrater reliability of .68 (Zanarini et al., 2000).

Beck Depression Inventory-Second Edition (BDI-II; Beck, Steer, and Brown, 1996). The BDI-II is a 21-item self-report measure that was used to assess depression in the clinical sample. It has good internal consistency (alpha $=.92)($ Beck et al., 1996). The average BDI-II score in the clinical group was $21.4(S D=12.40)$, indicating a moderate level of depression.

Structured clinical interview. A structured clinical interview was developed as seen in Table 1. The aim was to undertake a descriptive clinical study to investigate the hypotheses that were outlined in Shafran et al.'s (2002) cognitive-behavioural model of clinical perfectionism (e.g. resetting standards higher following both success and failure); therefore a structured interview to specifically assess these hypotheses was used rather than 
Table 1. Structured clinical interview questions

Section 1 - Motivation to change:

1. Do you see yourself as being a perfectionist and having high standards?

2. Is being a perfectionist a useful thing for you?

3. Is being a perfectionist an unhelpful thing for you?

4. Given the choice between giving up being a perfectionist and staying a perfectionist, what would you choose?

5. What would be the advantages of continuing to be perfectionistic?

6. What would be the disadvantages of continuing to be perfectionistic?

7. What would be the advantages of not being perfectionistic anymore?

8. What would be the disadvantages of not being perfectionistic anymore?

Section 2 - Failure to meet high standards:

9. Can you tell me about the areas in your life that you hold high standards for yourself?

10. Choose one area where you have high standards for yourself and tell me about a recent example where you failed to meet up to the standard you set yourself.

11. Considering that situation, what does it say about you as a person that you failed to meet this standard?

12. What is the worst thing about the fact that you failed to meet this standard?

13. Do you think of yourself as a failure for not having met this standard?

14. Did not meeting the standard cause you distress or upset?

15. Did it cause others distress or upset?

16. How long after failing to meet this standard did you continue to think about it?

17. What other factors about you do you think might have attributed to you not meeting this standard?

18. What other factors not about you do you think might have attributed to you not meeting this standard, like external events or other people?

19. What have you learned from this situation where you failed to meet your standard?

20. Due to the situation, will you re-evaluate your standards and set them higher or lower?

the usual technique of open questioning utilized in qualitative research (Denzin and Lincoln, 2000). The questions were based on clinical knowledge regarding motivation to change and cognitive therapy techniques to access cognitions about failure.

\section{Procedure}

The research was approved by the Curtin University Ethics Committee. Interviews were conducted at Curtin University with the clinical group, and interviews with athletes were conducted either at the participant's home or place of work. The interviews were audiotaped and transcribed by the first author. The time of interviews varied between 20 minutes to 1 hour, and the average interview time was 35 minutes.

\section{Results}

The data were analysed by a qualitative, inductive content analysis for key themes by the first author through multiple readings until theme saturation was reached. It is acknowledged that the interpretation of themes may have been influenced by this author's prior knowledge; 
Table 2. Summary of themes identified regarding motivation to change perfectionism and self-evaluation following failure

\begin{tabular}{|c|c|c|}
\hline Question area & Clinical group themes & Athlete group themes \\
\hline $\begin{array}{l}\text { Advantages of } \\
\text { perfectionism }\end{array}$ & $\begin{array}{l}\text { Gain respect from others } \\
\text { Helps to achieve goals }\end{array}$ & Helps to achieve goals \\
\hline $\begin{array}{l}\text { Disadvantages of } \\
\text { perfectionism }\end{array}$ & $\begin{array}{l}\text { Stress, anxiety, depression } \\
\text { Pressure to succeed } \\
\text { Interpersonal consequences } \\
\text { i.e. annoying to others }\end{array}$ & $\begin{array}{l}\text { Interpersonal consequences i.e. } \\
\text { put pressure on others }\end{array}$ \\
\hline $\begin{array}{l}\text { Choice to keep or } \\
\text { relinquish perfectionism }\end{array}$ & $\begin{array}{l}\text { Keep perfectionism as there } \\
\text { are more advantages }\end{array}$ & $\begin{array}{l}\text { Keep perfectionism, could not } \\
\text { change }\end{array}$ \\
\hline Consequences of change & $\begin{array}{l}\text { Catastrophic consequences if } \\
\text { change perfectionism }\end{array}$ & $\begin{array}{l}\text { None reported as would not } \\
\text { change perfectionism }\end{array}$ \\
\hline $\begin{array}{l}\text { Evaluation of self after } \\
\text { failure to meet a standard }\end{array}$ & $\begin{array}{l}\text { Failure as a person if do not } \\
\text { meet a standard } \\
\text { Dichotomous evaluation of } \\
\text { self as "not good enough" }\end{array}$ & $\begin{array}{l}\text { Not a failure as a person if do not } \\
\text { meet a standard Making } \\
\text { mistakes is normal and means } \\
\text { you are human }\end{array}$ \\
\hline $\begin{array}{l}\text { Resetting standards } \\
\text { following failure }\end{array}$ & $\begin{array}{l}\text { Set standards the same or } \\
\text { higher next time }\end{array}$ & $\begin{array}{l}\text { Set standards the same or lower } \\
\text { next time }\end{array}$ \\
\hline
\end{tabular}

however, the themes were also analysed independently by the final author, who concurred with the themes, although suggested some combination of themes from the first author's initial reading of the data. A summary of the themes identified can be seen in Table 2 .

\section{Motivation to change perfectionism}

Perceived benefits of perfectionism and advantages of continuing perfectionism. A major theme emerging from the clinical group was ambivalence regarding whether they thought perfectionism was not useful in response to question 2 (see Table 1). Of the participants who thought it was not useful a typical response was:

No... because I get stressed out about a lot of things that I don't need to [C4].

The clinical participants who gave mixed responses stated benefits:

Possibly because it means that I've got an area of my life that's actually working [C3].

In contrast, the athletes viewed it as useful where the majority (8 participants) reported benefits such as:

It makes my life easier. . if I didn't have goals then my life would be less meaningful [A2].

A major theme emerging from the clinical participants was that perfectionism is useful, which the majority endorsed in response to question 5. The most common reason cited was helping to achieve high standards:

I have certain standards in my life that I want to get to, I need that sort of thing to help me aim towards where I want to go [C2]. 
Another theme reported was gaining respect from others due to perfectionism:

You gain respect, you're organized, there's less stress [C6].

Other people may acknowledge that, so it's something that somebody else can say about you that's positive [C3].

One interesting response reported despite these advantages was that it was not effective:

People look at you as being very reliable, very trustworthy, someone who has impeccable high standards, that is someone you might want to have working for them. . .so an advantage in that way is people think highly of you, as long as they don't know the internal bit that it's not actually very effective [C1].

The athletes all reported advantages of perfectionism related to achieving goals:

Achieving goals, professionally, personally, socially, it helps to achieve goals basically [A2].

Perceived negative consequences of perfectionism and disadvantages of continuing perfectionism. The majority of the clinical group (8 participants) reported that perfectionism was unhelpful in response to question 4, while one stated it was not unhelpful, and another that it was both. This revealed a theme of pressure to succeed. Typical responses about why it was unhelpful included:

I hate that being someone that has to have it all so right because it puts too much pressure on me, and that then leads to all sorts of other things like you feel depressed, or angry so in that way it's not helpful [C6].

In comparison, the athlete group was split between stating that perfectionism was unhelpful (4 participants), helpful (4 participants), and 2 participants reported both. Of the athletes who thought it was unhelpful, all cited interpersonal reasons:

Sometimes it can be a nuisance because even with my wife I set too high standards and you put a lot of pressure on other people because you expect the same as what you expect of yourself [A1].

In response to question 6 the clinical group mainly reported disadvantages (8 participants). The responses pointed to emotional distress and pressure on others:

I guess it can be annoying to other people sometimes if they don't have the same sort of standards that you do, it can cause a bit of friction, also you can get a bit frustrated with yourself if you haven't done something well [C2];

I guess I have low self-esteem because of it, it's just like everything has to be done right, or not done at all, and there's sort of no medium ground for anything [C5].

Six athletes reported disadvantages, whereas the remainder reported no disadvantages. Of those who reported disadvantages, all involved interpersonal consequences:

It gets on lots of people's nerves... [A6].

Choice to keep or relinquish perfectionism. In question 3 participants were asked if they had the choice, would they choose to give up or keep perfectionism. The main theme to emerge across groups was that individuals would choose to keep perfectionism. Seven of the clinical 
participants stated they would prefer to keep their perfectionism, while 3 stated they would like to change. The clinical participants who did not want to change made statements pointing to the positive benefits of perfectionism:

I would stay one [a perfectionist]. I just think there are more advantages, like I said it helps with my achievements [C2].

A main theme to emerge from the clinical group was of catastrophic cognitions regarding what would happen if they attempted to change perfectionism, represented by the following quotes:

I would probably stick with it. ..I would feel like the wheels would be falling off if I wasn't perfectionistic [C3];

I think I would have to say that I would stay the perfectionist because then I have some hope of achieving, if I let go of that, it is when I would sink [C7].

The athlete group were similar as 9 participants stated they would keep their perfectionism. Typical responses emphasized they were happy with perfectionism and that they could not change:

I don't think I could choose not to have high standards, because I guess that's how I see myself [A7].

\section{Cognitions about failure to meet high standards}

Perception of being a failure and consequences of not meeting standards. Participants gave a detailed example in response to question 10 as indicated in Table 3. In response to the meaning of not meeting a standard, 7 clinical participants indicated they believed they were a failure, revealing a clear theme of perception of being a failure:

For me it's not good enough...I can run through my head that other people might say that it's good, but I find that hard to accept. And even though I got 79\%, I mean that's a good mark, but it doesn't feel like it [C7].

This quote revealed a theme in the clinical group that clearly embodies dichotomous thinking. In contrast, no athletes reported negative evaluations of self and some responded that they did not fail:

No I didn't really fail to meet it because I didn't know what I was capable of achieving, so I was not disappointed [A10],

whilst others responded that making mistakes is normal:

That I'm human, that I can make mistakes as well! That you can't do everything well all the time [A5].

In response to viewing their self as a failure (question 13) the majority of clinical participants (7 participants) agreed strongly:

Yes, absolutely. . .I believe it's honestly my fault. . .[C6]. 
Table 3. Clinical and athlete participants' examples of failure to meet a high standard

\begin{tabular}{lc}
\hline Example & Number reporting issue \\
\hline Clinical group: & 2 \\
Not finishing study & 1 \\
Being too critical of their child & 1 \\
Failing to do a good job of making an invitation & 1 \\
Not doing a good job of a dinner party & 1 \\
Not helping enough on a voluntary committee & 1 \\
Not packing correct clothes for a holiday & 1 \\
Being behind on housework & 1 \\
Making a mistake at work & 1 \\
Running late to an appointment & 3 \\
Athlete group: & 2 \\
Did not perform in race in desired time (poor performance) & 1 \\
Did not finish a race & 1 \\
Not recovering from knee injury fast enough & 1 \\
Not training enough for triathlon recently & 1 \\
Not handling a work situation well & 1 \\
Not putting enough time into work & \\
Not being a good friend to someone & \\
\hline
\end{tabular}

In contrast, all athletes stated they did not see themselves as being a failure:

No, definitely not. I'm achieving quite a bit [A10].

Consequently, the main theme that appeared to emerge from athletes was that making mistakes is normal and that they had not failed, whilst the clinical group theme was regarding being not good enough and a failure as a person.

Clinical participants referred to a variety of negative consequences of not having met a standard in response to question 12. Four participants mentioned negative emotions:

I guess the worst thing about it is that I did generate a lot of stress in myself [C5].

Another 2 clinical participants reported worrying that others would think badly of them. In contrast, only 3 athletes stated there was no negative consequence, but of those who did, some reported disappointment:

...in the morning, you have to face yourself in the mirror, and think that I was too soft, and not tough enough to do the race... [A1].

\section{Failure to meet standards causing distress to self and others}

In response to asking if not meeting their standard caused them distress (questions 14), 9 clinical participants agreed. However, when asked if not meeting their standard caused others distress (question 15), an equal proportion responded yes (4 participants) and no (4 participants), while the remainder were unsure. Of those who said it caused others distress, they cited others' reactions to their own distress: 
Well yes it does because obviously he [partner] knows when I'm upset and it makes him upset [C1].

However, the athlete group had a reverse pattern, where 8 stated it did not cause them distress, and 9 stated that it did not cause others distress:

Disappointment more than stress or upset. ..I'm fairly realistic in my goal setting therefore if you don't achieve it you know it's not the end of the world [A8].

\section{Perceived factors contributing to not meeting a standard}

The clinical participants responded with a range of reasons that contributed to them not meeting their standard in response to question 17. Three participants cited internal attributions:

It just come down to laziness in the end and making excuses. . . [C2].

One responded that it was perfectionism itself:

The mere fact that I am a perfectionist, because it would be very hard to meet that standard. . because it's always just out of reach [C1].

In contrast, no athletes reported internal attributes:

In the big scheme of things, it's not the end of the world. . .it was just an unfortunate sequence of events [A3].

In response to external factors that contributed to not meeting a personal standard (question 18), half of the clinical participants reported an external factor such as time demands on them, or actions of other people. Two clinical participants said there were no external factors. However, 9 out of the 10 athletes cited external reasons for not meeting their standard, for example the weather "It was a cold morning" [A10] and luck "I think that I was just unlucky getting excessive scar tissue" [A6].

\section{What was learned from not meeting a personal standard}

There was a range of responses from the clinical group to question 19. A typical response was about trying harder:

Just that you do need to put the effort in to get where you want to go [C2].

Other responses highlighted the repetitive nature of their perfectionism:

Absolutely nothing because I repeat the behaviour [C8].

In contrast some athletes emphasized flexibility regarding standards:

I think you need to have flexibility no matter what you do because you can't always stick rigidly to what you want to do because there might be other factors outside of what you have control [A2].

One athlete emphasized learning their standard was not that important: 
I guess just that it's not really that important...there are so many other things that are more significant [A8].

\section{Re-evaluation of personal standards}

In response to the question asking if they would re-evaluate their standards and set them higher or lower following failure (question 20), none of the clinical participants stated they would set their standard lower. The majority (7 participants) stated that they would not change their standards:

I don't know that my standards ever move, because I think they are always impossibly high [C5]

and 3 participants stated they would set their standards higher:

Well I constantly try and set it higher, to do a better job next time [C9];

I would probably actually set them higher, which is part of the trap I suppose [C7].

In contrast, half of the athletes reported that their standard would stay the same while the other half said they would set their standard lower:

I guess in the whole scheme of things, I might have to set them a little lower [A3].

\section{Discussion}

The aim of this study was to investigate contrasting groups' views of motivation to change perfectionism, self-evaluation and resetting standards following failure. In summary, both the clinical and athlete group perceived many advantages and they would not want to change perfectionism. The clinical group reported catastrophic cognitions regarding changing perfectionism, viewed their self as a failure if they did not meet a standard, and in some cases would reset standards higher following failure, which was different to the athletes who did not report these themes. These results will be explored in more detail as follows.

\section{Motivation to change}

There was a common theme in the clinical and athlete groups in regards to perceived benefits of perfectionism, where both reported perfectionism helping to achieve goals. However, the clinical group also reported a different theme to athletes, namely about gaining respect of other people due to achievements. This personal versus interpersonal theme appeared to be one of the key differences between the two groups. This suggests that an area to target when considering motivation to change in clinical groups is the perception of other people valuing them as a person due to achievement.

In regards to negative consequences of perfectionism, the clinical group reported negative emotions, poor self-esteem, and negative impact on others. The athletes perceived less negative consequences but did, however, note the impact of perfectionism on interpersonal relationships, which is consistent with Hewitt and Flett's (1991) conceptualization of perfectionism impacting on interpersonal relationships. 
One of the most interesting findings was in regards to the question about whether participants would choose to keep or relinquish their perfectionism. The majority of the clinical group stated they would keep their perfectionism rather than change it. This is a very important finding as, despite reporting many negative consequences of perfectionism, the clinical group preferred not to change perfectionism. This is important as it is the first study to date to investigate motivation to change perfectionism in a clinical sample and the results indicate that participants state they do not wish to change perfectionism. The main reasons cited were because it helps with achievements, feeling valued by others, and that if they were to give up perfectionism something catastrophic would occur, e.g. "I would feel like the wheels would be falling off if I wasn't perfectionistic". This is a similar finding to Riley and Shafran (2005), where participants reported a catastrophic fear of failure if perfectionism was to be relinquished: "It would just be a total loss of security if I fell from this standard" (p. 373). Riley and Shafran labelled this theme as motivation for perfectionism, and this highlights the importance of addressing ambivalence to change, as it has been argued that perfectionists may not wish to relinquish their perfectionism due to benefits (Lundh, 2004).

The results suggest that at the start of treatment for perfectionism it would be useful to directly challenge catastrophic predictions about what may happen if perfectionism is changed. Furthermore, to state that treatment is not about trying to lower their standards, rather it is about reducing their overdependence of self-evaluation on striving to meet unrealistically high standards (for further details see Shafran et al., 2010).

\section{Cognitions about failure}

One of the differences between the groups was the degree of negative self-evaluation regarding not meeting a standard. While the clinical group made internal attributions about failure, the athletes reported they had not failed. This fits with attribution theories of depression of internal, global and stable negative attributions (Abrahamson, Seligman and Teasdale, 1978). While the clinical group made negative internal attributions, many athletes cited external reasons for failure, for example being unlucky or the weather. This difference in attribution style may be one factor that accounts for differences in distress due to not meeting a standard.

Another difference between groups was that the athlete group did not report dichotomous thinking about not meeting a personal standard, e.g. "I'm human. .I can make mistakes as well...you can't do everything well all the time" whilst the clinical group viewed their performance in a dichotomous manner, stating "absolutely" and "definitely" in response to whether they viewed their self as a failure. This supports the central role of dichotomous thinking in maintaining clinical perfectionism (Shafran et al., 2002, 2010). Another prediction from Shafran et al.'s (2002, 2010) model is that individuals with clinical perfectionism constantly re-set their standards higher following success and failure. Although some of the clinical group stated their standards would stay the same, the remainder responded that they would set them higher, whilst the athletes stated they would stay the same or set them lower, which lends support to Shafran et al.'s $(2002,2010)$ model.

\section{Strengths and limitations}

One of the strengths of the study was that qualitative studies in the area of perfectionism are lacking and the results of this study provided rich, in-depth data from a clinical group who 
were elevated in negative perfectionism. The results are not necessarily generalizable due to the small sample size, and it is possible that themes are not representative. However, the results can inform theory and future quantitative studies in motivation to change in perfectionism.

A limitation of the study was that the participants were not provided with a definition of perfectionism, and thus it is possible that they may have responded to questions based on different definitions. It would be useful for future research to either provide an operational definition of perfectionism or to ask participants "what, in your opinion, is perfectionism?" Another limitation is that despite being very experienced competitors, the athletes were at an amateur level and older than typical elite or professional level athletes. Consequently, their responses may be different from an elite athlete group, and it would be useful for future research to include professional athletes in comparison to a clinical group.

\section{Conclusions}

The results suggest that future research needs to be directed towards developing ways to enhance motivation to change in treatment for perfectionism. The finding that the majority of a clinical group did not want to change their perfectionism may be an important factor that has been overlooked when considering treatment for perfectionism, and thus clinicians may need to focus more explicitly on this area through motivational interviewing and other techniques to enhance motivation to change.

\section{References}

Abrahamson, L. Y., Seligman, M. E. P. and Teasdale, J. D. (1978). Learned helplessness in humans: critique and reformulation. Journal of Abnormal Psychology, 87, 49-74.

Beck, A. T., Steer, R. A. and Brown, G. K. (1996). Beck Depression Inventory Manual ( $2^{\text {nd }}$ ed.). San Antonio: Harcourt Brace and Company.

Bieling, P. J., Summerfeldt, L. J., Israeli, A. L. and Antony, M. M. (2004). Perfectionism as an explanatory construct in comorbidity of axis I disorders. Journal of Psychopathology and Behavioral Assessment, 26, 193-201.

Denzin, N. D. and Lincoln, Y. S. (2000). Handbook of Qualitative Research. Thousand Oaks, Ca: Sage Publications.

Egan, S. J., Piek, J. P., Dyck, M. J. and Rees, C. S. (2007). The role of dichotomous thinking and rigidity in perfectionism. Behaviour Research and Therapy, 45, 1813-1822.

Egan, S. J., Wade, T. D. and Shafran, R. (2011). Perfectionism as a transdiagnostic process: a clinical review. Clinical Psychology Review, 31, 203-212.

First, M. B., Spitzer, R. L., Gibbon, M., Williams, J. B. W. and Benjamin, L. (1994). Structured Clinical Interview for DSM-IV Axis II Personality Disorders (SCID-II). Version 2.0. New York: Biometrics Research Department, New York State Psychiatric Institute.

First, M. B., Spitzer, R. L., Gibbon, M. and Williams, J. B. W. (1996). Structured Clinical Interview for DSM-IV Axis I Disorders - patient edition (SCID-I/P, Version 2.0). New York: Biometrics Research Department, New York State Psychiatric Institute.

Frost, R. O., Marten, P., Lahart, C. and Rosenblate, R. (1990). The dimensions of perfectionism. Cognitive Therapy and Research, 14, 449-468.

Haase, A. M., Prapavessis, H. and Owens, R. G. (1999). Perfectionism and eating attitude in competitive rowers: moderating effects of body mass index, weight classification and gender. Psychology and Health, 14, 643-657. 
Haase, A. M., Prapavessis, H. and Owens, R. G. (2002). Perfectionism, social physique anxiety and disordered eating: a comparison of male and female athletes. Psychology of Sport and Exercise, 3, 209-222.

Hagger, M. S. and Chatzisarantis, N. L. D. (2011). Never the twain shall meet? Quantitative psychological researchers' perspectives on qualitative research. Qualitative Research in Sport, Exercise and Health, 3, 266-277.

Hewitt, P. L. and Flett, G. L. (1991). Perfectionism in the self and social contexts: conceptualization, assessment and association with psychopathology. Journal of Personality and Social Psychology, 60, 456-470.

Lundh, L. G. (2004). Perfectionism and acceptance. Journal of Rational-Emotive and CognitiveBehaviour Therapy, 22, 255-269.

Neumeister, K. L. (2004). Interpreting successes and failures: the influence of perfectionism on perspective. Journal for the Education of the Gifted, 27, 311-335.

Rice, K. G., Bair, C. J., Castro, J. R., Cohen, B. N. and Hood, C. A. (2003). Meanings of perfectionism: a quantitative and qualitative analysis. Journal of Cognitive Psychotherapy, 17, 3958.

Riley, C. and Shafran, R. (2005). Clinical perfectionism: a preliminary qualitative analysis. Behavioural and Cognitive Psychotherapy, 33, 369-374.

Shafran, R., Cooper, Z. and Fairburn, C. G. (2002). Clinical perfectionism: a cognitive behavioural analysis. Behaviour Research and Therapy, 40, 773-791.

Shafran, R., Egan, S. and Wade, T. (2010). Overcoming Perfectionism: a self-help guide using cognitive behavioural techniques. London: Constable and Robinson.

Stoeber, J. and Otto, K. (2006). Positive conceptions of perfectionism: approaches, evidence, challenges. Personality and Social Psychology Review, 10, 295-319.

Terry-Short, L. A., Owens, R. G., Slade, P. D. and Dewey, M. E. (1995). Positive and negative perfectionism. Personality and Individual Differences, 18, 663-668.

Wilson, G. T. and Schlam, T. R. (2004). The transtheoretical model and motivational interviewing in the treatment of eating and weight disorders. Clinical Psychology Review, 24, 361-378.

Zanarini, M. C., Skodol, A. E., Bender, D., Dolan, R., Sanislow, C., Schaeffer, E., et al. (2000). The collaborative longitudinal personality disorders study: reliability of Axis I and II diagnoses. Journal of Personality Disorders, 14, 291-299. 